\title{
Expression of two conserved leptospiral antigens in Escherichia coli
}

\author{
J.P. DOHERTY, B. ADLER, J.I.ROOD, S. J.BILLINGTON and S. FAINE
}

Department of Microbiology, Monash University, Clayton, Victoria 3168, Australia

\begin{abstract}
Summary. The genes encoding two protein antigens of Leptospira interrogans serovar pomona were cloned and expressed in Escherichia coli. Rabbit antisera raised against the cloned proteins, designated p12 and p20, were used to identify the antigens in Western blots of disrupted leptospiral cells. The proteins p 12 and p 20 were conserved within the genus Leptospira and were not detected in Leptonema illini. Although both proteins were present in leptospiral outer envelope preparations they did not elicit the production of agglutinating or opsonising antibodies.
\end{abstract}

\section{Introduction}

Leptospirosis is an acute, febrile, bacteraemic disease caused by serovars of Leptospira interrogans. Leptospiral antigens are clearly important in the classification of the organism (Johnson and Faine, 1984), the diagnosis of the disease (Faine, 1982), and immunity to the disease (Adler and Faine, 1978, 1983). Many different antigens have been extracted from leptospires (Faine, 1974) but these have mostly been in crude preparations containing complex mixtures of antigens. With the exceptions of lipopolysaccharide (LPS) (Ono et al., 1982, 1984; Jost et al., 1986; Farrelly et al., 1987), the individual antigens have not been identified or characterised. As with many other gram-negative bacteria (Gregory, 1986), it has proved extremely difficult to obtain preparations of individual antigens which are not contaminated with LPS (Kelson et al., 1988).

Molecular cloning and expression of leptospiral antigens in Escherichia coli offers the potential of a reproducible source of individual leptospiral antigens. Therefore, we chose this approach to obtain antigens for subsequent study of their roles in classification, diagnosis and immunity.

\section{Materials and methods}

\section{Bacterial strains and plasmids}

Serovars of $L$. interrogans, L. biflexa and Leptonema illini (see table) described previously (Adler and Faine, 1983) were cultured in Tween 80-bovine albumin (EMJH)

Received 16 Feb. 1988; revised version accepted 15 Aug. 1988. medium with added pyruvate (Johnson et al., 1973). All $E$. coli recombinants were derivatives of strain JFM65 (Rood et al., 1980) or strain DH $5 \alpha$ (BRL, USA) and were cultured in $2 \times$ YT medium (Vieira and Messing, 1982). All recombinant plasmids were derivatives of the cloning vector pUC18 (Norrander et al., 1983) and were designated with a pLBA prefix. The plasmids pLBAl and pLBA4 were selected by their ability to code for the production of leptospiral antigens. These plasmids contain $8 \cdot 2-\mathrm{kb}$ and $5 \cdot 6-\mathrm{kb} P$ st I fragments of $L$. interrogans serovar pomona DNA, respectively. Plasmid pLBA7 is a deletion derivative of pLBA1. Plasmids pLBA8 and pLBA9 are pUC18-derived recombinants which contain a fragment of pLBA4.

\section{Antigen preparation}

Preparations of $E$. coli were made in a French press as follows. Cultures $(800 \mathrm{ml})$ of the recombinant strains were grown overnight at $37^{\circ} \mathrm{C}$. After centrifugation at $3000 \mathrm{~g}$ for $10 \mathrm{~min}$ at $4^{\circ} \mathrm{C}$, the cells were resuspended in

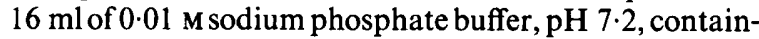
ing $\mathrm{NaCl} 0.85 \% \mathrm{w} / \mathrm{v}$ (PBS) and then disrupted by protrusion through a pre-cooled $\left(4^{\circ} \mathrm{C}\right)$ French Pressure Cell (Aminco, Silver Spring, MD, USA) at about $138 \mathrm{MPa}$. Cell debris was removed by centrifugation at $500 \mathrm{~g}$ for $15 \mathrm{~min}$ at $4^{\circ} \mathrm{C}$ and the supernatant fluid stored at $-20^{\circ} \mathrm{C}$ in $2-\mathrm{ml}$ volumes.

Ammonium sulphate fractionation of French-pressed E. coli preparations was done at $4^{\circ} \mathrm{C}$. A saturated solution of $\left(\mathrm{NH}_{4}\right)_{2} \mathrm{SO}_{4}$ was added drop by drop to a 2-ml volume of extract, until the required concentration was obtained. The solution was stirred for $30-60 \mathrm{~min}$ and then centrifuged at $7700 \mathrm{~g}$ for $15 \mathrm{~min}$. The supernate was decanted and subjected to further addition of $\left(\mathrm{NH}_{4}\right)_{2} \mathrm{SO}_{4}$ as required. The precipitates obtained from each sequential fractionation step were resuspended in a minimal volume of PBS, dialysed extensively against PBS diluted 1 in 10 , adjusted to a final volume of $2 \mathrm{ml}$, and stored at $-20^{\circ} \mathrm{C}$. 
Table. Detection of p12- and p20-related antigens in serovars of $L$. interrogans, $L$. biflexa and $L$. illini by immunoblotting with rabbit antisera against cloned antigens

\begin{tabular}{|c|c|c|c|c|}
\hline \multirow{2}{*}{$\begin{array}{l}\text { Serogroup of } \\
\text { L. interrogans }\end{array}$} & \multirow[b]{2}{*}{ Serovar } & \multirow{2}{*}{$\begin{array}{l}\text { Strain } \\
\text { no. }\end{array}$} & \multicolumn{2}{|c|}{$\begin{array}{l}\text { Immunospecific } \\
\text { staining with } \\
\text { antiserum to }\end{array}$} \\
\hline & & & p12 & p20 \\
\hline Pomona & pomona & $\mathrm{L} 10$ & + & + \\
\hline Pomona & kennewicki & L245 & + & + \\
\hline Pomona & mozdok & L306 & + & + \\
\hline Pomona & proechimys & L304 & + & + \\
\hline Australis & australis & L168 & + & + \\
\hline Autumnalis & bim & L267 & + & + \\
\hline Ballum & arborea & L264 & + & + \\
\hline Bataviae & bataviae & L263 & + & + \\
\hline Canicola & canicola & $\mathrm{L} 128$ & + & + \\
\hline Cynopteri & cynopteri & $\mathrm{L} 243$ & + & + \\
\hline Celledoni & celledoni & L242 & + & + \\
\hline Djasiman & djasiman & $\mathrm{L} 181$ & + & + \\
\hline Grippotyphosa & grippotyphosa & L174 & + & + \\
\hline Hebdomadis & hebdomadis & L182 & + & + \\
\hline \multicolumn{5}{|l|}{ Icterohaemorr- } \\
\hline hagiae & copenhageni & L136 & + & + \\
\hline Javanica & javanica & L183 & + & + \\
\hline Mini & szwajizak & L198 & + & + \\
\hline Panama & panama & L184 & + & + \\
\hline Pyrogenes & zanoni & L178 & - & + \\
\hline Sarmin & sarmin & L224 & + & + \\
\hline Sejroe & hardjo & L13 & + & + \\
\hline Shermani & shermani & L244 & + & + \\
\hline Tarassovi & tarassovi & L169 & + & + \\
\hline \multicolumn{5}{|l|}{ Serovars of $L$. } \\
\hline biflexa & andamana & L286 & + & + \\
\hline & bebrich & L284 & - & + \\
\hline & maritza & L283 & - & - \\
\hline & patoc & L41 & - & - \\
\hline & sobradinho & L287 & + & + \\
\hline Leptonema illini & & L89 & - & - \\
\hline
\end{tabular}

Leptospiral sonicates were prepared as before (Adler et al., 1980b). Leptospiral outer envelope was isolated from $L$. interrogans serovar copenhageni strain L136 by the method of Auran et al. (1972).

\section{Serological methods}

Microscopic agglutination tests (MAT) were performed as described by Adler and Faine (1976). The methods for generation and measurement of the chemiluminescence response by phagocytic cells ingesting opsonised leptospires were as described by McGrath et al. (1984) with mouse peritoneal macrophages. Macrophages were harvested and prepared as described by Jost et al. (1986). Antiserum against whole leptospires of serovar pomona served as a positive control in the agglutination and opsonisation tests.

\section{Preparation and analysis of DNA}

Whole-cell DNA was prepared from $L$. interrogans serovar pomona strain L10 as described by Marshall et al. (1981). After extraction with phenol and chloroform, the DNA was precipitated with ethanol (2 volumes, $\left.-20^{\circ} \mathrm{C}\right)$ and purified by ultra-centrifugation in a caesium chlorideethidium bromide density gradient. The ethidium bromide was removed by extraction with isopropanol saturated with $\mathrm{NaCl}$ and the DNA was dialysed against tris (hydroxymethyl) aminomethane-ethylene diamine tetra-acetic acid (tris-EDTA) buffer, pH 8.0 (Maniatis et al., 1982). E. coli plasmid DNA was purified as described by Young et al. (1978). Small scale plasmid preparations were made by the rapid boil procedure (Holmes and Quigley, 1981).

Ligation and transformation methods were as described by Burns et al. (1983) and Dagert and Ehrlich (1979). Electrophoresis of DNA samples was performed in $0.8-1.2 \%$ agarose in a horizontal gel apparatus with a tris acetate (pH 7.8) electrode buffer system (Young et $a l ., 1978)$. Restriction endonucleases and calf intestinal alkaline phosphatase (molecular biology grade) from Boehringer-Mannheim (Penzberg, FRG) were used throughout. T4 DNA ligase was obtained from New England Biolabs (Beverly, MA, USA).

\section{Colony immunoassay}

Recombinant clones were grown on $2 \times Y \mathrm{~T}$ agar containing ampicillin $100 \mu \mathrm{g} / \mathrm{ml}$, replicated on to nitrocellulose filters (BA85, Schleicher and Schuell) and lysed by exposure to sodium dodecyl-sulphate (SDS) $1 \% \mathrm{w} / \mathrm{v}$ and chloroform vapour (Kempet al., 1983). After vigorous washing in $50 \mathrm{~mm}$ tris-saline buffer, $\mathrm{pH} 7.4$ (TBS), the filters were treated with rabbit antiserum as described for the immunoblotting procedure. The antiserum was prepared against whole, live $L$. interrogans serovar pomona strain L10 as described previously (Chapman et al., 1987), absorbed twice with whole $E$. coli strain JFM65 for $2 \mathrm{~h}$ on ice and used at a dilution of 1 in 400 in Tween $200.05 \% \mathrm{v} / \mathrm{v}$ in TBS.

\section{Electrophoresis and immunoblotting}

Leptospiral and $E$. coli components were separated by electrophoresis on discontinuous $15 \% \mathrm{w} / \mathrm{v}$ SDS-polyacrylamide gels (Laemmli, 1970). French-pressed E. coli preparations and leptospiral sonicates were prepared in $0.04 \mathrm{M}$ tris- $\mathrm{HCl}$ buffer, $\mathrm{pH} 6.8$, containing SDS $1.3 \% \mathrm{w} /$ $\mathrm{v}$, bromophenol blue $0.002 \% \mathrm{w} / \mathrm{v}$ and glycerol $4 \% \mathrm{w} / \mathrm{v}$ and immersed in boiling water for $2 \mathrm{~min}$. Samples of protein, $25 \mu \mathrm{g} /$ lane, were electrophoresed at $30 \mathrm{~mA} / \mathrm{gel}$ until the dye was near the bottom of the gel. The resolved material was transferred to nitrocellulose $(0.45-\mu \mathrm{m}$ pore size; Schleicher and Schuell) in a Biorad Transblot cell by the method of Towbin et al. (1979) with a 1 in 2 dilution of transfer buffer.

Antigenic components were detected by immunostaining as described by Chapman et al. (1987), except 
that the incubation with primary antibody was performed overnight at room temperature. This treatment was followed by incubation at $37^{\circ} \mathrm{C}$ for $4 \mathrm{~h}$ with the appropriate horseradish peroxidase-conjugated secondary antibody - either goat anti-rabbit IgG (Bio-Rad, Richmond, CA, USA) or rabbit anti-human IgG (Silenus, Melbourne, Australia). 4-Chloro-1-naphthol (Merck, Darmstadt, FRG) was used as the chromogen (Hawks et al., 1982).

To determine whether the antigens were sensitive to proteinase, nitrocellulose filters containing SDS-PAGEseparated leptospiral sonicates were incubated in PBS containing Proteinase K (Sigma, St Louis, MO, USA; $100 \mathrm{mg} / \mathrm{ml}$ ) for $24 \mathrm{~h}$ at $37^{\circ} \mathrm{C}$. After thorough washing in PBS they were immunostained as described previously. To determine if the antigens were sensitive to reduction, dithiothreitol $10 \mathrm{mg} / \mathrm{ml}$ was added to the electrophoresis samples just before boiling.

\section{Preparation of rabbit antisera against cloned antigens}

French-pressed preparations of $E$. coli strains JFM65 (pLBA1) and DH5 $\alpha$ (pLBA9) were fractionated by sequential ammonium sulphate precipitation and fractions were tested by Western blot analysis to determine if they were enriched for the cloned antigens. The $0-20 \%$ and $0-30 \%$ ammonium sulphate fractions, respectively, were emulsified with Freund's incomplete adjuvant $(1: 1 \cdot 2, \mathrm{v}: \mathrm{v})$ and used to immunise New Zealand White rabbits. The corresponding fractions from $E$. coli strains JFM65 or DH $5 \alpha$, containing only the vector pUC18, were used to immunise control rabbits. The rabbits were given intradermal injections of $0.1 \mathrm{ml}$ of emulsified antigen at six sites and were bled 4 weeks later.

Antiserum was also prepared against the cloned antigen of $20 \mathrm{kda}$ (p20) by the method of Boulard and Lecroisey (1982). The equivalent Coomassie blue-stained regions were excised from gels of SDS-PAGE-separated preparations of the $E$. coli strain DH5 $\alpha$ containing pLBA9 or pUC18. The excised bands were macerated, emulsified with adjuvant and injected into rabbits as described previously. Rabbits were given a booster injection without adjuvant 4 weeks after the first injection and were bled after a further 3 weeks.

\section{Cloning of leptospiral antigens}

DNA purified from $L$. interrogans serovar pomona strain $\mathrm{L} 10$ was digested with Bam HI, ligated to BamHIdigested, alkaline phosphatase-treated vector plasmid pUC18, and used to transform E. coli JFM65 to ampicillin resistance. The resultant gene bank of 1000 recombinant clones was then screened by colony immunoassay. Two recombinant plasmids, pLBA1 and pLBA4, which coded for the production of leptospiral antigens were obtained. Plasmids pLBA7, a deletion derivative of pLBA1, and pLBA8 and pLBA9, subclones of pLBA4, were constructed as described in fig. 2.

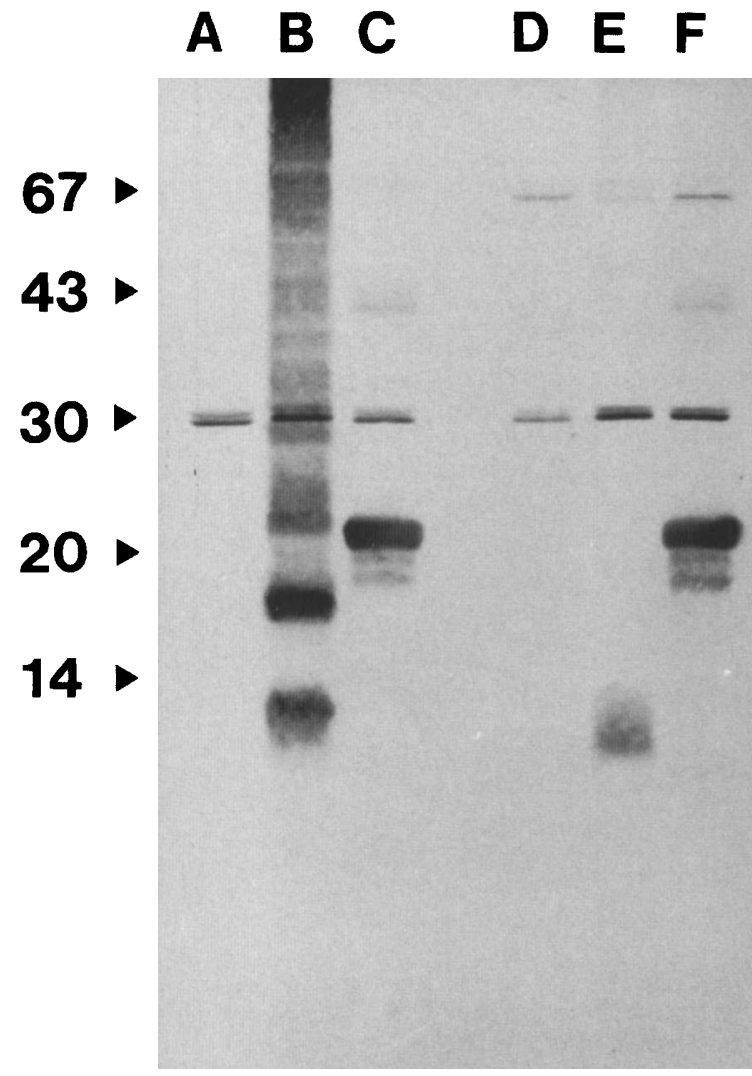

Fig. 1. Immunoblot of $E$. coliclones stained with rabbit antiserum against $L$. interrogans serovar pomona strain L10. Cell extracts were prepared from $E$. coli JFM65 cells which contained the following plasmids: lanes A and D, pUC18; lanes B and E, pLBA1; lanes C and F, pLBA4. Samples in lanes D, E and F were pretreated with dithiothreitol. The positions of molecular weight markers (Kda) are indicated.

\section{Results}

\section{Cloning of leptospiral antigens}

Screening of the $E$. coli gene bank revealed the presence of four clones which expressed antigens that reacted with rabbit antiserum to $L$. interrogans serovar pomona. Two of these clones, containing plasmids pLBA1 and pLBA4, were studied further. Cell extracts of the two recombinants were prepared in a French press and were examined by immunoblotting (fig. 1). The results showed that plasmid pLBAl coded for a dithiothreitol-sensitive antigen which yielded a multiple banded profile and that plasmid pLBA4 coded for an antigen of $20 \mathrm{Kda}$, designated p20. Restriction maps of pLBA1 and pLBA4 were prepared by digestion with endonucleases and are shown in fig. 2. Subcloning of pLBA1 localised the gene encoding the expressed 

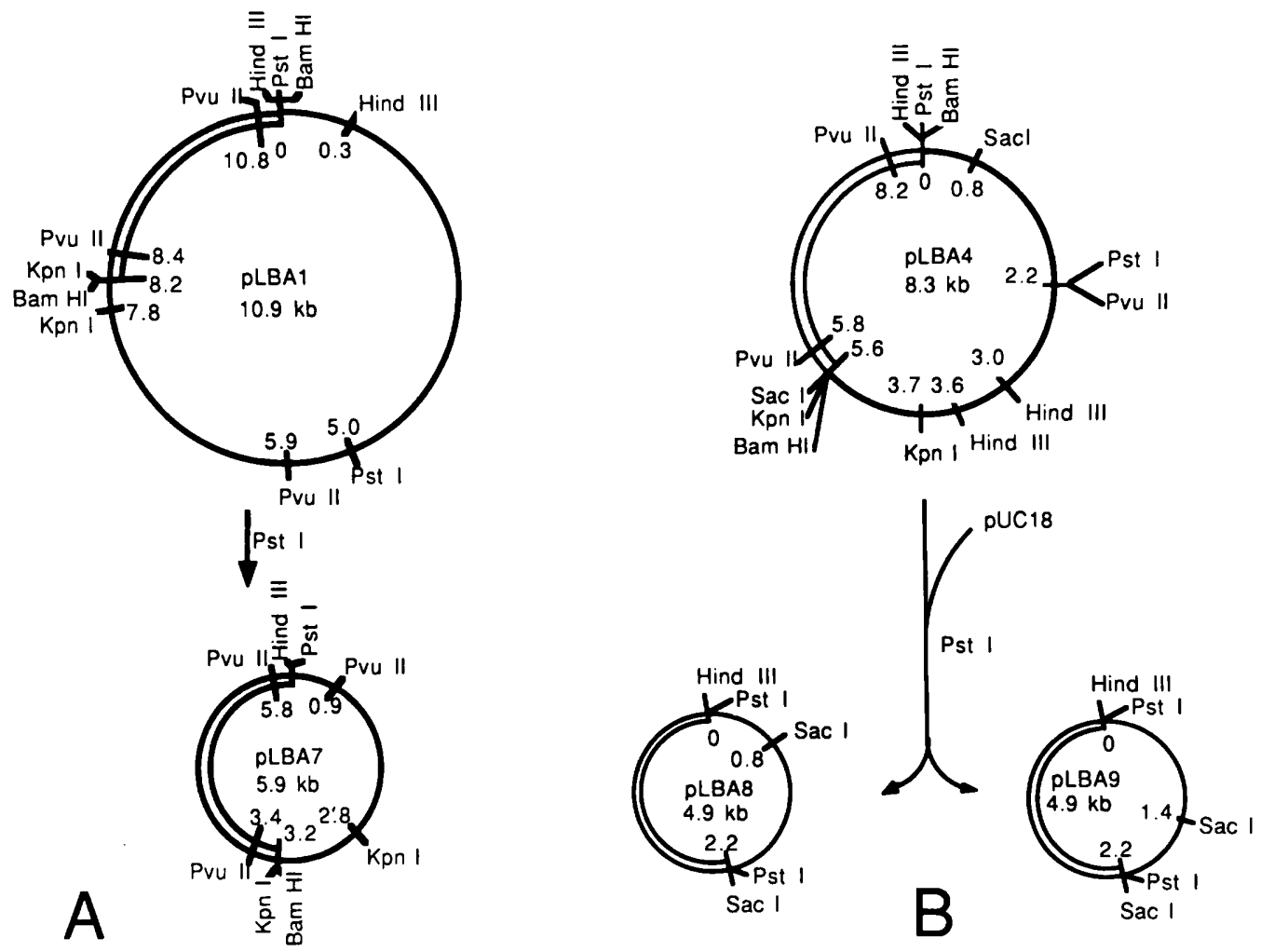

Fig. 2. Derivation and restriction maps of recombinant plasmids. The blocked area represents the pUC18 portion of the plasmids. Sizes are in kilobase pairs (kb). The deletion plasmid pLBA7 was isolated (A) by digestion of pLBA1 with PstI, religation, and transformation of strain DH5 $\alpha$ to ampicillin resistance. The subclones pLBA8 and pLBA9 each contain the same $2 \cdot 2-\mathrm{kb} P s t \mathrm{I}$ fragment from pLBA4 but in opposite orientations (B). These plasmids were isolated after digestion of pLBA4 with Pst and ligation of the resultant DNA fragments into PstI-digested pUC18 DNA. Ampicillin resistant derivatives of strain DH5 $\alpha$ were selected.

leptospiral antigen to a $3 \cdot 2-\mathrm{kb}$ Pst l fragment contained on pLBA7. pLBA8 and pLBA9, two subclones of pLBA4, contained a $2 \cdot 2-\mathrm{kb}$ Pst 1 fragment in opposite orientations (fig. 2). The p20 antigen was detected in both subclones by immunoblotting. However, plasmid pLBA9, which contained the fragment in the opposite orientation to pLBA4, showed a marked increase in the level of expression of the antigen, to the extent that p20 was clearly visible on Coomassie blue-stained polyacrylamide gels (fig. 3).

\section{Antisera against cloned antigens}

Rabbit antisera were prepared against p20, the pLBAl-encoded antigens, and the appropriate controls, as described in methods. These antisera were used to immunostain transblots of $L$. interrogans serovar pomona sonicate (fig. 4). Antisera raised against the cloned antigen encoded by pLBA1 recognised a single band of $12 \mathrm{Kda}$ in the leptospiral sonicate. This antigen was designated p12. Each of the antisera raised against p20 recognised a band of $20 \mathrm{Kda}$ in leptospiral extracts. Prior treatment of the leptospiral sonicate with proteinase $\mathrm{K}$ abolished the reactivity of both $\mathrm{p} 22$ and p20 (fig. 4) indicating that they were proteins. The p12 antigen was also sensitive to treatment with dithiothreitol.

Immunoblot analysis demonstrated that both antigens were present in an outer-envelope extract of $L$. interrogans serovar copenhageni strain L136. As potential surface antigens, $\mathrm{p} 12$ and $\mathrm{p} 20$ could be involved in immunity to infection by eliciting agglutinating or opsonising antibodies. However, the antisera raised against these antigens did not agglutinate whole leptospires in microscopic agglutination tests, nor did they opsonise leptospires for phagocytosis by mouse macrophages.

The antisera were used to immunostain transblots of sonicates of representative serovars of $L$. interrogans, L. biflexa and L. illini (table); 23 serovars from 20 serogroups of $L$. interrogans and five serovars from five serogroups of $L$. biflexa were 


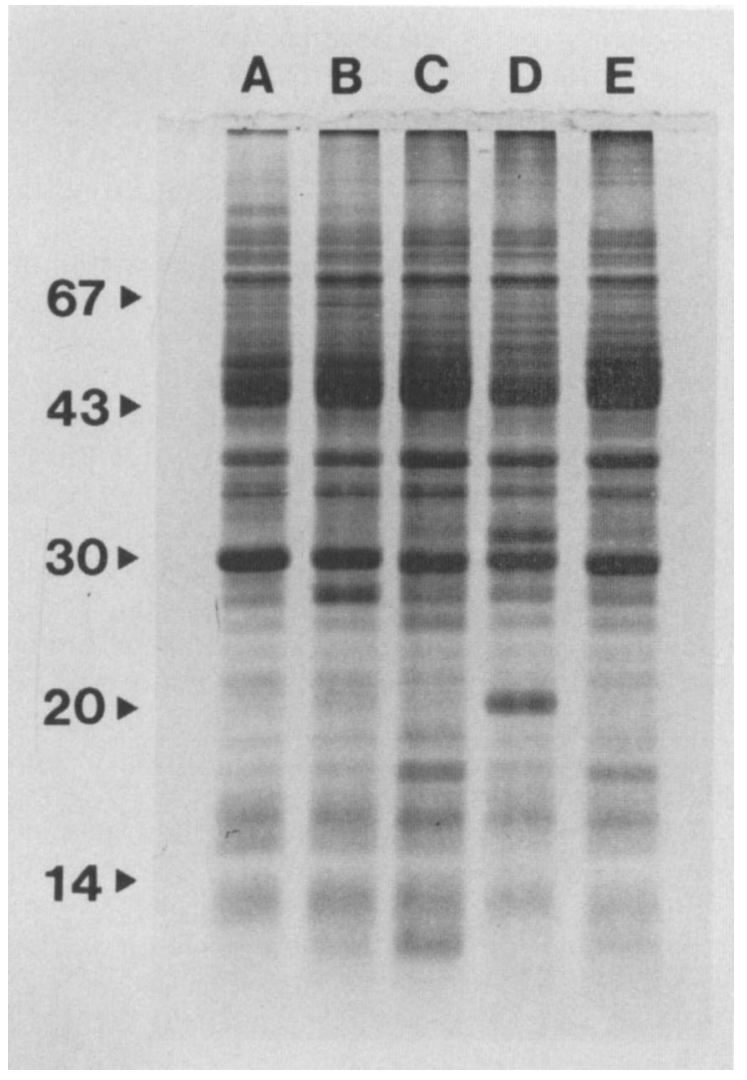

Fig. 3. SDS-PAGE of cell extracts from E. coli clones: lane A, JFM65 (pUC18); lane B, JFM65 (pLBA4); lane C, DH5 $\alpha$ (pLBA8); lane D, DH5 $\alpha$ (pLBA9); lane E, DH5 $\alpha$ (pUC18). The positions of molecular weight markers $(\mathrm{Kda})$ are indicated.

examined. The antigen p20 was detected in all 23 $L$. interrogans serovars and in three of the five $L$. biflexa serovars. Similarly, antigen $\mathrm{p} 12$ was detected in all but one, serovar zanoni strain L178, of the 23 $L$. interrogans serovars, and in two of the five $L$. biflexa serovars. The apparent molecular weight of the antigen designated $\mathrm{p} 12$ varied from $11 \mathrm{Kda}$ to $14 \mathrm{Kda}$ in different serovars. Neither of the antigens p1 2 or p20 was detected in L. illini.

\section{Discussion}

Others have cloned and obtained expression of leptospiral genes in $E$. coli, but they did not investigate the antigenic properties of the cloned products. For example, Yelton and Cohen (1986) cloned a tryptophan synthesis gene from the saprophyte L. biflexa, and Dain et al. (1985) cloned the haemolysin gene of $L$. interrogans serovar pomona. These authors did not investigate the antigenic properties of their cloned products but

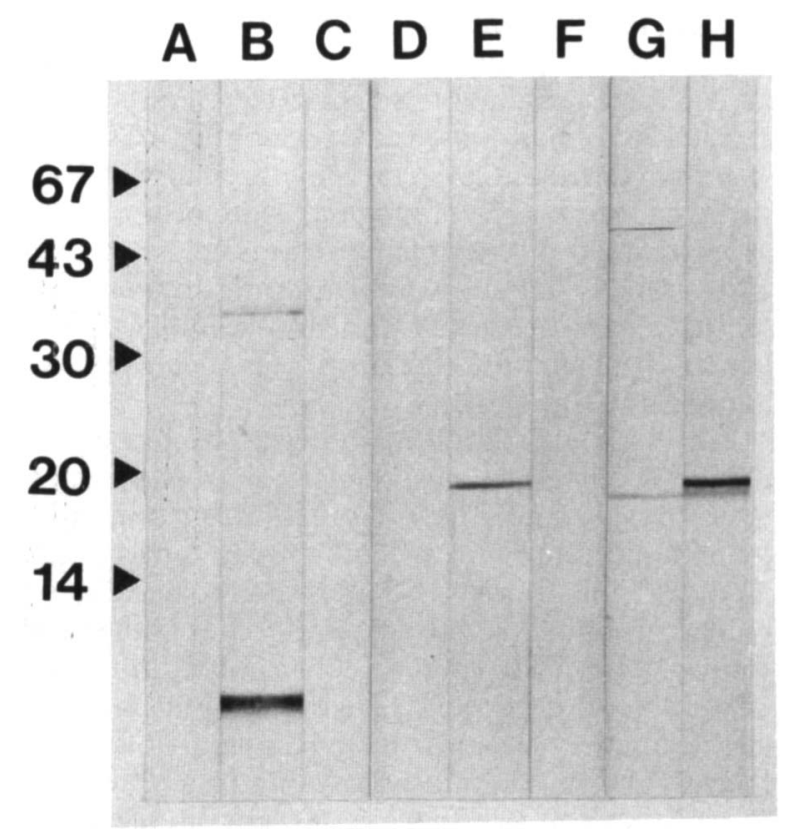

Fig. 4. Immunoblot of $L$. interrogans serovar pomona strain L10 sonicate stained with rabbit antisera raised against the antigens, p12 and p20: lane A, 0-20\% ammonium sulphate fraction of JFM65 (pUC18); lanes B and C, 0-20\% ammonium sulphate fraction of JFM65 (pLBA1); lane D, 20-kda region from SDSPAGE gel of DH5 $\alpha$ (pUC18); lanes $E$ and $F, 20-k d a$ region from SDS-PAGE gel of DH5 $\alpha$ (pLBA9); lane G; $0-30 \%$ ammonium sulphate fraction of $\mathrm{DH} 5 \alpha(\mathrm{pUC1})$; lane $\mathrm{H}, 0-30 \%$ ammonium sulphate fraction of DH5 $($ pLBA9). Lanes $\mathrm{C}$ and $\mathrm{F}$ were treated with proteinase $\mathrm{K}$ before immunostaining. Molecular weight markers (Kda) are indicated.

examined their role in metabolism or pathogenesis, respectively.

In this study two leptospiral protein antigens were cloned and expressed in $E$. coli. Rabbit antisera raised against the cloned antigens were used to identify the native antigens in Western blots of leptospiral sonicate. Both antigens were proteins as demonstrated by their inactivation by proteinase $K$. The antigen encoded by the recombinant plasmid pLBA4 had a molecular weight of 20000 in both its cloned and native forms. Subcloning of pLBA4 localised the p20 structural gene to a $2 \cdot 2-\mathrm{kb} P s t$ fragment contained in opposite orientations in plasmids pLBA8 and pLBA9. Both subclones expressed the p20 antigen; however, strains with pLBA9, which contained the fragment in the opposite orientation to pLBA4, showed a marked increase in the level of expression of the antigen. These results suggest that in pLBA4 and pLBA8 the gene encoding the p20 leptospiral antigen is expressed from its own promoter, whereas 
in pLBA9 the gene is orientated such that its expression is controlled by a promoter carried on the pUC18 portion of the plasmid. The second antigen (p12) had a molecular weight of 12000 in its native form, but appeared to either adhere nonspecifically to $E$. coli components, or to be produced in aggregated or fragmented forms in $E$. coli. In both cloned and native forms this antigen was sensitive to treatment with dithiothreitol, indicating that disulphide bonding was necessary to maintain its antigenicity.

Both p12 and p20 were shown to be present in the outer envelope of $L$. interrogans and could, therefore, play potential roles in inducing immunity to infection. Immunity to leptospirosis is humorally mediated and appears to depend on the production of agglutinating and opsonic antibodies (Adler and Faine, 1977; Adler et al., 1980a, b; McGrath et al., 1984; Jost et al., 1986). However, rabbit antisera raised against the antigens p12 and p20 did not have agglutinating and opsonising properties. Although both antigens were present in the outer envelope preparation they may not be exposed on the surface of the organism but embedded at the base of the LPS, as has been postulated for some outer membrane proteins in other gram-negative bacteria (Sawada et al., 1984). Indeed, an outer membrane protein not exposed on the bacterial surface has been identified by monoclonal antibodies in leptospires of serovar copenhageni (Jost et al., 1988). We do not yet have sufficient information to assign definite structural locations or roles to $\mathrm{p} 12$ or p20.

The rabbit antisera were also used to determine the distribution of the two antigens within the genus Leptospira and in the closely related Leptonema species, L. illini, formerly classified as Leptospira. Antigen p20 was detected in all serovars and p12 was detected in all but one of the serovars tested of the pathogenic species $L$. interrogans. Both antigens were detected in some but not all serovars of the non-pathogenic species $L$. biflexa; neither was detected in L. illini. Thus, both p12 and p20 appear to be conserved antigens within the genus Leptospira and, as such, may have structural or metabolic roles. The absence of $\mathrm{p} 12$ in L. interrogans serovar zanoni and of both antigens in some serovars of $L$. biflexa may be due to the functions of these

\section{REFERENCES}

Adler B, Faine S 1976 Susceptibility of mice treated with cyclophosphamide to lethal infection with Leptospira interrogans serovar pomona. Infection and Immunity 14: 703708 . components being performed by antigenically different proteins in these serovars. As the current method of classification of leptospires relies solely on the agglutinating antigens, little is known about the relationship and specificity of non-agglutinating antigens within this classification.

The broad distribution of the antigens within the genus would seem to preclude a role in immunity following natural infections, as immunity to leptospirosis is at best serogroup specific. The lack of agglutinating or opsonic activity in antisera against either $\mathrm{p} 12$ or $\mathrm{p} 20$ is consistent with this hypothesis. However, results with rabbit antisera may not necessarily give an accurate indication of the specificity or significance of the antigens in naturally acquired infections of man and other species. Therefore, we are examining sera from human leptospirosis patients for antibodies against the two cloned antigens. Preliminary results indicate that some naturally-infected patients produce antibodies against p12 and p20.

Serodiagnosis of leptospirosis usually depends upon the MAT, which requires the use of whole, viable leptospires. Genus-specific antigen preparations have been used for diagnosis in various procedures such as passive haemolysis (Cox et al., 1957), passive haemagglutination (Palit and Gulasekharam, 1973) and enzyme immunoassay (Terpstra et al., 1980). A reported advantage of these tests was their tendency to become positive earlier than the MAT; however others have reported high falsepositive rates due to cross-reactions with saprophytic leptospires (Bragger and Adler, 1976). Furthermore, the prerequisite of growing large quantities of leptospires for antigen has limited the use of some of the tests. It is possible that both these problems may be overcome by the use of cloned antigens which are found either exclusively or predominantly in the pathogenic species $L$. interrogans. Further studies are aimed at determining whether the cloned antigens p 12 and p 20 could be used for this purpose.

This work was supported by a research grant from the National Health and Medical Research Council, Canberra, Australia. We thank B. H. Jost for preparation of leptospiral outer envelope.

Adler B, Faine S 1977 Host immunological mechanisms in the resistance of mice to leptospiral infections. Infection and Immunity 17: 67-72.

Adler B, Faine S 1978 The antibodies involved in the human immune response to leptospiral infection. Journal of Medical Microbiology 11 : 387-400. 
Adler B, Faine S 1983 A pomona serogroup-specific, agglutinating antigen in Leptospira, identified by monoclonal antibodies. Pathology 15: 247-250.

Adler B, Faine S, Muller H K, Green D E $1980 a$ Maturation of humoral immune response determines the susceptibility of guinea-pigs to leptospirosis. Pathology 12: 529-538.

Adler B, Murphy A M, Locarnini S A, Faine S $1980 b$ Detection of specific anti-leptospiral immunoglobulins $M$ and $G$ in human serum by solid-phase enzyme-linked immunosorbent assay. Journal of Clinical Microbiology 11 : 452-457.

Auran N E, Johnson R C, Ritzi D M 1972 Isolation of the outer sheath of Leptospira and its immunogenic properties in hamsters. Infection and Immunity 5: 968-975.

Boulard C, Lecroisey A 1982 Specific antisera produced by direct immunization with slices of polyacrylamide gel containing small amounts of protein. Journal of Immunological Methods 50: 221-226.

Bragger J M, Adler B 1976 A card test for the serodiagnosis of human leptospirosis. Journal of Clinical Pathology 29: 198202.

Burns D M, Abraham L J, Beacham I R 1983 Characterization of the ush gene of Escherichia coli and its protein products. Gene 25: 343-353.

Chapman A J, Adler B, Faine S 1987 Genus-specific antigens in Leptospira revealed by immunoblotting. Zentralblatt für Bakteriologie, Mikrobiologie und Hygiene A 264: 279-293.

Cox C D, Alexander A D, Murphy L C 1957 Evaluation of the hemolytic test in the serodiagnosis of human leptospirosis. Journal of Infectious Diseases 101 : 210-218.

Dagert M, Ehrlich S D 1979 Prolonged incubation in calcium chloride improves the competence of Escherichia coli cells. Gene 6: 23-28.

Dain A A, Rozinov M N, Golltsmaier T A, Gershanovich V N, Chemukha I u G 1985 Cloning and the expression of the hemolysin gene of Leptospira pomona in Escherichia coli. Zhurnal Mikrobiologii, Epidemiologii i Immunobiologii (7), 710.

Faine S 1974 Leptospiral antigens. Folia Facultatis Medicae, Universitatis Comenianae Bratislaviensis 12: Suppl 57-74.

Faine S (ed) 1982 Guidelines for the control of leptospirosis. WHO Offset Publication No. 67, World Health Organization, Geneva.

Farrelly H E, Adler B, Faine S 1987 Opsonic monoclonal antibodies against lipopolysaccharide antigens of Leptospira interrogans serovar hardjo. Journal of Medical Microbiology 23: 1-7.

Gregory R L 1986 Microbial ribosomal vaccines. Reviews of Infectious Diseases 8: 208-217.

Hawks R, Niday E, Gordon J 1982 A dot immunobinding assay for monoclonal and other antibodies. Analytical Biochemistry 119: 142-147.

Holmes D S, Quigley M 1981 A rapid boiling method for the preparation of bacterial plasmids. Analytical Biochemistry 114: 193-197.

Johnson R C, Walby J, Henry R A, Auran N E 1973 Cultivation of parasitic leptospires: effect of pyruvate. Applied Microbiology 26: 118-119.

Johnson R C, Faine S 1984 Leptospira Noguchi, 1917. In: Krieg N R, Holt J G (eds) Bergey's Manual of systematic bacteriology, 9th edn, Vol. 1. Williams and Wilkins, Baltimore, pp 62-67.

Jost B H, Adler B, Vinh T, Faine S 1986 A monoclonal antibody reacting with a determinant on leptospiral lipopolysaccharide protects guinea pigs against leptospirosis. Journal of Medical Microbiology 22: 269-275.

Jost B H, Adler B, Faine S 1988 Reaction of monoclonal antibodies with species specific determinants in Leptospira interrogans outer envelope. Journal of Medical Microbiology 27: 51-57.

Kelson J S, Adler B, Chapman A J, Faine S 1988 Identification of leptospiral flagellar antigens by gel electrophoresis and immunoblotting. Journal of Medical Microbiology 26: 4753.

Kemp D J, Coppel R L, Cowman A F, Saint R B, Brown G V, Anders R F 1983 Expression of Plasmodium falciparum blood-stage antigens in Escherichia coli: detection with antibodies from immune humans. Proceedings of the National Academy of Science of the USA 80: 3787-3791.

Laemmli U K 1970 Cleavage of structural proteins during the assembly of the head of bacteriophage T4. Nature 227:680 685.

Maniatis T, Fritsch E F, Sambrook J 1982 Molecular cloning. A laboratory manual. Cold Spring Harbor Laboratory, New York, pp. 93-94.

Marshall R B, Wilton B E, Robinson A J 1981 Identification of Leptospira serovars by restriction-endonuclease analysis. Journal of Medical Microbiology 14: 163-166.

McGrath H, Adler B, Vinh T, Faine S 1984 Phagocytosis of virulent and avirulent leptospires by guinea-pig and human polymorphonuclear leukocytes in vitro. Pathology 16: 243249.

Norrander J, Kempe T, Messing J 1983 Construction of improved M13 vectors using oligodeoxynucleotide-directed mutagenesis. Gene 26: 101-106.

Ono E, Naiki M, Yanagawa R 1982 Production and characterization of monoclonal antibodies to lipopolysaccharide antigen of Leptospira interrogans serovar kremastos and canicola. Zentralblatt für Bakteriologie, Mikrobiologie und Hygiene A 252: 414-424.

Ono E, Naiki M, Yanagawa R 1984 Isolation of antigenic oligosaccharide fraction from Leptospira interrogans serovar canicola with a monoclonal antibody. Journal of General Microbiology 130: 1429-1435.

Palit A, Gulasekharam J 1973 Genus-specific leptospiral antigen and its possible use in laboratory diagnosis. Journal of Clinical Pathology 26: 7-16.

Rood J I, Laird A J, Williams J W 1980 Cloning of the Escherichia coli $\mathrm{K}-12$ dihydrofolate reductase gene following MU-mediated transposition. Gene 8: 255-265.

Sawada S, Suzuki M, Kawamura T, Fujinaga S, Masuho Y, Tomibe K 1984 Protection against infection with Pseudomonas aeruginosa by passive transfer of monoclonal antibodies to lipopolysaccharides and outer membrane proteins. Journal of Infectious Diseases 150 : 570-576.

Terpstra W J, Ligthart G S, Schoone G J 1980 Serodiagnosis of human leptospirosis by enzyme-linked-immunosorbentassay (ELISA). Zentralblatt für Bakteriologie Mikrobiologie und Hygiene A 247: 400-405.

Towbin H, Staehelin T, Gordon J 1979 Electrophoretic transfer of proteins from polyacrylamide gels to nitrocellulose sheets : procedure and some applications. Proceedings of the National Academy of Science of the USA 76: 4350-4354.

Vieira J, Messing J 1982 The pUC plasmids an M13mp7derived system for insertion mutagenesis and sequencing with synthetic universal primers. Gene 19: 259-268.

Yelton D B, Cohen R A 1986 Analysis of cloned DNA from Leptospira biflexa serovar patoc which complements a deletion of the Escherichia coli trpE gene. Journal of Bacteriology 165 : 41-46.

Young I G, Jaworowski A, Poulis M I 1978 Amplification of the respiratory NADH dehydrogenase of Escherichia coli by gene cloning. Gene 4: 25-36. 